\section{Розина В.А.}

канд. полит. наук, соискатель ГОУ ВО МО «Московский Государственный Областной Университет», г. Москва

e-mail: neutour@yandex.ru

\section{Rozina V.A.}

Candidate of Political Sciences, Moscow Region State University, Moscow

e-mail: neutour@yandex.ru

\section{Современные российские медиафакторы как средство развития политической консьюмеризации}

\begin{abstract}
Аннотация
Изучено влияние средств массовой информации на актуальные тенденции политического рынка, сделан вывод о возникновении так называемых медиасракторов, то есть факторов воздействия средств массовой информации на политику. По мнению автора, эти тенденции появляются на медиарынке самостоятельно, но при этом обладают собственным влиянием на политическую жизнь. По наблюдениям, чаще всего медиафакторы возникают в тех ссрерах где средства массовой информации отходят от привычных ролей (например, коммуникативной, идеологической, организующей, социальной и других), что в свою очередь вызвано определенными социальными и экономическими тенденциями. Отдельно и более подробно исследовано влияние медиафакторов на консьюмеризацию политической сферы жизни - тренд, характеризующийся появлением черт экономического рынка в политическом процессе. Отмечено, что благодаря этой тенденции политический рынок отчасти начинает функционировать подобно классическому рынку спроса и предложения, на нем появляются маркетинговые и рекламные технологии. Автором учтены причины возникновения и развития самой консьюмеризации, среди которых политический абсентеизм, деидеологизация, глобализация рынков, экономическая нестабильность. Дано как определение, так и собственная классификация медиафакторов, рассмотрены в общих чертах причины их появления с учетом современного состояния рынка средств массовой информации, происходящих на нем процессов технической модернизации и конвергенции жанров, а также текущей политики по госрегулированию медиаотрасли. Также проанализированы способы и возможности влияния каждого из пяти рассмотренных медиафакторов на политическую жизнь, в том числе консьюмеризацию. Сделан прогноз дальнейшего развития явления, в частности сделаны выводы о том, что медиафакторы способствуют росту консьюмеристкой тенденции.
\end{abstract}

\section{Ключевые слова:}

медиафракторы, медиарынок, консьюмеризация, общество потребления, общественный выбор, конвергенция, деидеологизация.

\section{Actual Russian media factors as resourse of development of political consumerism}

\section{Abstract}

The influence of the media on current trends in the political market has examined in this article, in particular, a conclusion about the appearance of the media factors - the factors of influence of media on politics has made. According to the author's opinion, these trends appear on the media market independently, but at the same time they have great influence on political life. According to bservations, most often media factors appear in the spheres, where the media are moving away from traditional roles (for example, communicative, ideological, organizing, socia and others) which in turn has caused by certain social and economic trends.

Separately and in more detail, the author studies the influence of media factors on the consumerism of the political sphere of life - the trend, which is characterized by the appearance of features of the economic market in the political process. It has noted, that due to this trend, the political market partly begins to function like the classical market of supply and demand, in particular, there appear marketing and advertising technologies. The author takes into consideration the causes of the emergence and development of consumerizm itself, including political absenteeism, deideologization, globalization of markets and economic instability. It has given both definition and classification of media factors, the reasons for their appearance, taking into account the current state of the media market, the processes of technical modernization and convergence of genres, as well as the current state media policy have considered. Also the ways and possibilities of influence of each of the five considered media factors on political life, including consumerism have analysed. The forecast for the further development of the phenomenon has created, in particular, it was concluded, that media factors promotes the growth of consumeristic tendency.

\section{Keywords:}

media factors, media market, consumerism, consumer society, public choice, convergence, deideologization.

(C) The Author(s), 2018 This is an open access article under the CC BY 4.0 license (http://creativecommons.org/licenses/by/4.0/)

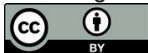


Современное состояние политического рынка характеризуется таким явлением, как консьюмеризация. Этот термин, происходящий от английского слова consumer (покупатель), означает появление в политической жизни черт экономического рыночного процесса. А в более узком смысле - прагматичное поведение как политиков, так и электората, при котором и те, и другие ставят во главу угла решение материальных проблем, а не реализацию идеологических программ [3; 13].

В некотором смысле этот тренд стал своего рода неизбежным спутником как экономического роста, так и «общества потребления» (достаточно вспомнить этапы становления чикагской теории общественного выбора, которая стала предтечей современных консьюмеристских течений) [14]. Однако тенденция, которая в 1960 гг. воспринималась как частная и далеко не самая распространенная, в настоящее время активно набирает обороты.

К факторам роста консьюмеризации ряд исследователей относит возрастающую деполитизацию населения, политический абсентеизм, нарастающую глобализацию, а также - влияние медиа [8]. Будучи по традиционной своей роли посредниками между объектами и субъектами политического рынка, средства массовой информации (далее - СМИ), тем не менее, способны оказывать свое воздействие на протекающие политические процессы [1].

Эти выводы подводят к введению понятия медиафакторов (от лат. factor - движущий, производящий), т. е. факторов влияния СМИ на политический процесс. Иначе можно сформулировать, что медиафакторы - тенденции, которые самопроизвольно возникают на рынке СМИ, но при этом обладают влиянием на политическую жизнь. По наблюдениям, как правило, они появляются в тех сферах, в которых пресса отходит от своих привычных ролей.

Рассмотрим, о каких ролях идет речь. Журналистику принято считать «полифункциональной системой», обладающей рядом функций - коммуникативной, организаторской, идеологической, социально-ориентирующей, культурно-образовательной, рекламно-справочной, рекреативной [7]. Даже из этого перечня видно, что минимум 4 роли (коммуникативная, организаторская, рекламно-справочная, рекреационная) обусловлены скорее возникновением общественного спроса, а не попытками СМИ реализовать собственную независимую политику [5].

Исследование явления подводит к выводу о существовании медиафакторов коммерциализации, интернетизации, конвергенции, госрегулирования и популяризации. Это деление носит предварительный характер - дальнейшее изучение рынка может показать наличие новых медиафакторов, более того, роли уже существующих могут трансформироваться. Однако на сегодняшний момент представляется целесообразным остановиться на такой классификации.

Медиафактор коммерциализации проявляется в формировании коммерческих форм работы СМИ, при которых медиа вместо своих основных ролей стремятся к извлечению максимальной прибыли. Их поведение меняется, информативная и образовательная функции отходят на второй план. Газеты и журналы становятся предприятиями, основной целью которых является привлечение средств, а эффективность измеряется не качеством выпускаемой информации, а принесенным доходом.

Возникновение этого явления обусловлено непростой финансовой и административной ситуацией на рынке СМИ, при которой медиа поставлены в сложные финансовые условия, их роль не регламентирована, а понятие функционала сильно размыто [9].

Надо отметить, что коммерческая составляющая, конечно, не является единственным направлением в работе СМИ. Медиа продолжают выполнять информационную, просветительскую, интегрирующую работу. Но все же, извлечение прибыли становится превалирующей целью. И в итоге тенденция к коммерциализации приводит к появлению отдельных форм коммерческой деятельности СМИ.

Применение брендирования и других рекламных приемов дает возможность отметить появление еще одного медиафактора - популяризации, т. е. замены серьезной аналитики легкими и намеренно развлекательными материалами. Средства массовой информации стараются подстроиться под запросы читателей, что приводит к намеренному упрощению и адаптации информации.

Литературное качество медиасообщений снижается, а при их выпуске используются приемы, почерпнутые из рекламного бизнеса. Информация становится своего рода товаром, который СМИ пытаются в буквальном смысле слова продать. Этот товар должен обладать определенными потребительскими свойствами, которые медиа изо всех сил пытаются ему придать, чтобы - «продвинуть» на рынок. Строго говоря, этот процесс имеет много общего с продажей обычной продукции.

Б. Л. Борисов полагает, что для политика доступ к СМИ становится основным способом самоидентификации. «Так называемый свободный доступ к СМИ в реальности обладает рядом специфических особенностей, являясь могучим инструментом манипулирования», - отмечает автор [2, с. 348].

Также на рынке можно отметить появление медиафактора госрегулирования - постепенного перехода 
медиа под начало государственных органов власти, позволяющее последним влиять на процесс поиска, обработки и передачи информации.

Госрегулирование СМИ остается одной из актуальных тенденций современной медиасферы [11]. Поиск старых и совершенствование новых форм управления, которые способствовали бы как решению информационных задач, так и обеспечению финансовой и экономической безопасности изданий, - одно из наиболее важных направлений в современной журналистике.

Медиасегмент служит коммуникативной площадкой для взаимосвязи федерального центра с обширной региональной территорией, для восприятия и формирования там актуальной идеологической позиции. Региональные СМИ помогают более широкому осмыслению и внутренних, местных проблем, а также донесению их до широкой аудитории.

Важно отметить, госрегулирование не является тормозом для развития отрасли, как это порой предполагается. Медиауправление дает возможность государству проводить в жизнь информационную политику, направленную на консолидацию общества. Играют свою роль медиа и во взаимоотношениях власти и электората. Социальные отношения имеют коммуникативную природу, власть коммуникативна сама по себе, и исходя из концепции Н. Лумана, у СМИ в государстве есть своя функция: «в той степени медиа должны удовлетворять, защищать интересы государства, власти, в какой степени государство, власть защищают интересы гражданского общества, каждой личности» [6, с. 9].

Внедрение новых технологий обеспечивает появление еще двух медиафакторов - интернетизации и конвергенции. Под медиафактором интернетизации можно понимать смещение сегмента СМИ в сторону интернет-технологий, появление онлайнпроектов. Если ранее термины «медиа» и «печатные СМИ» были почти синонимами, то в настоящее время скорее целесообразно говорить об интернетпорталах, как о наиболее активных игроках на рынке СМИ. В настоящее время практически все издания имеют интернет-версии своих бумажных аналогов, более того, многие медиа запускаются только в онлайн формате. И это не единственный аспект, позволяющий говорить о «всеобщей интернетизации». Важно то, что интернет-технологии проникли в сферы деятельности СМИ - от получения до обработки и передачи сведений. Изначально деятельность любой журналисткой организации состоит из получения, анализа, переработки и выпуска информации. Первый шаг - получение - неотъемлемо связан с источником информации (как правило, любой журналист стремится добиться эксклюзивности). И если ранее корреспонденты добывали информацию только в ходе общения с реальными ньюсмейкерами или из официальных документов, то теперь все чаще фигурируют интернет-источники. Это не только сайты государственных ведомств, но и популярные сообщества, блоги, сообщения на форумах и так далее.

Еще один медиафактор, связанный с введением технологических новшеств - медиафактор конвергенции.

Конвергенция (от лат. converge - приближаюсь) термин, который пришел в область общественных наук из естественно-научной сферы и подразумевает процессы схождения, взаимоуподобления. Применительно к СМИ это означает, слияние различных типов передачи информации в рамках одного издательского дома. Если раньше все СМИ были четко разделены по жанрам и способам распространения : печатные издания, радио, телевидение, то в последнее время на свет выпускаются мультимедийные продукты, которые имеют как бумажную, так и интернет-версию, а зачастую еще и радио или видеотрансляции. Журналистам приходится овладевать дополнительными навыками и быть не только пишущими репортерами, но и фотографами, видеооператорами, радиодиджеями и т. д. [10].

Под конвергенцией можно понимать слияние различных коммуникационных площадок: печатных СМИ, радио, телевидения, интернет-среды и так далее. В итоге, в журналистике конвергенция приводит к взаимообъединению прежде различных средств массовой информации: радио становится частью газеты, печатное издание входит в состав интернет-СМИ и т. д. Это в свою очередь приводит к объединению ранее разобщенных журналистских профессий, меняет представление о каналах коммуникаций и заставляет по-новому представлять будущее традиционных медиа [4].

Рассмотрим, как могут выделенные и отмеченные медиафакторы влиять на процесс консьюмеризации. Представляет интерес вопрос о том, как может проявляться это влияние, какие явления или действия можно считать его явным доказательством.

Если учитывать, что политический консьюмеризм - появление рыночных отношений в политическом процессе, то логично предположить, что действия СМИ, которые ведут к изменению мышления электората в этом направлении и к формированию у него прагматической оценки политиков могут служить явным доказательством влияния. Эта трансформация неотделима от прагматизации мышления, а соответственно от деидеологизированности 
населения. Соответственно, можно предположить, что факторы, которые способствуют уменьшению идеологической нагрузки, одновременно стимулируют и консьюмеризацию.

Представляется важным констатировать и еще одну корреляцию. Трансформация медиарынка находится в прямой зависимости от трансформации общества в целом. Издания меняются для удовлетворения пользовательских запросов, и соответственно, их модификация зависит от смены интересов самого социума. Преобладание прагматической компоненты, снижение идеологической составляющей вызывают соответствующие изменения в медийной сфере. Этот процесс взаимозависимый, он развивается по принципу цепной реакции: в обществе снижается запрос на информацию, падают продажи медиа продукции, возрастает экономическая напряженность на рынке СМИ, начинается борьба и стремление подстроиться под запросы читателей. Соответственно, это еще больше стимулирует прагматическую ориентацию электората, более того, для стимуляции читательского спроса издатели применяют определенные искусственные приемы (например, рассмотренная выше популяризация). В итоге возникает зависимость: СМИ стимулируют определенные качества читателей, те формируют пользовательский запрос, и медиа вынуждены ему следовать. Прагматизация населения растет, идеологическая зависимость наоборот снижается, и это стимулирует определенную политику СМИ. Таким образом, тренды общественного развития находят свой отклик на медиаполе, а особенности медиаполя стимулируют направления развития социума. Сам факт такого резонанса усиливает действие медиафакторов на консьюмеризацию.

Политики выступают в роли продавцов определенного товара, а электорат - потребителей, которые придирчиво и прагматично оценивают кандидатов и готовы расплатиться своими голосами только на предложение качественных услуг. Это тенденция безусловно стимулирует консьюмеристский тренд.

Проанализируем, как именно медиафакторы могут влиять на консьюмеризацию политической сферы жизни. Целесообразно предположить, что медиафактор популяризации приводит к упрощению подачи информации, стимуляции читательского спроса за счет апелляции к потребительским инстинктам, снижению идеологической, а подчас и смысловой нагрузки. Информация становится своего рода фастфудом, обладающим определенным качеством, однако призванным скорее утолить информационный голод потребителя, чем дать ему представление о высокой медиакухне. В итоге читатель воспринимает подаваемые через СМИ явления крайне упрощено, он видит только отдельные аспекты, он не склонен к сложной аналитике и т. д. Происходящие в области политики процессы он воспринимает как своего рода игру, в лучшем случае соревнование, а в худшем, но достаточно распространенном - как развлечение, шоу, в котором у электората одна задача - просто получить удовольствие от просмотра. Стоит ли говорить, что подобное несерьезное отношение и его самого настраивает на легкомысленный лад? И в таком случае, на первое место выходят прагматические мотивы.

Медиафактор госуправления приводит к возрастанию зависимости СМИ от органов власти, причем не столько федеральных, сколько местных, региональных. При этом освещение идет по одному направлению - это пиар заказчика, информирование общественности о его положительных инициативах, успешных начинаниях, планах на будущее и прочее. Соответственно, как правило, администрация в глазах читателей выглядит исключительно в положительном ключе. Это своего рода имидж, лишенный любых негативных черт, по-своему рекламный, и эта односторонность подачи, безусловно, не остается без внимания потребителя. Это приводит к тому, что электорат начинает воспринимать политиков как своего рода рекламные объекты, которые демонстрируют свои лучшие качества. Он относится к ним отчасти недоверчиво (как, впрочем, к любой рекламе), но ждет от них демонстрации определенных потребительских свойств.

Медиафактор интернетизации приводит к быстроте передачи информации, что косвенно снижает ценность аналитики. Новостной поток идет круглосуточно, в режиме нон-стоп, он достаточно плотен. Читатель только успевает задуматься над увиденной или прочитанной новостью, как ей на смену приходит еще несколько. Плюс увеличивается медийный охват благодаря размещению информации на сайтах, в соцсетях и так далее информацию видит большое количество людей. И аудитория не исчерпывается только зрителями передачи или читателями газеты - новости и материалы в интернете хранятся постоянно, выдаются по поиску в новостных агрегаторах и, соответственно, число просмотревших сообщения постоянно растет.

Информация распространяется быстро, и читатель гонится скорее за количеством, а не за качеством. Сложная аналитика, серьезные тексты, в том числе, конечно, политические, слишком трудны для восприятия. Мелкие новости с хлесткими заголовками становятся гораздо более популярными. 
И в итоге, это развивает общую деидеологизированность населения.

Медиафактор коммерциализации приводит к тому, что СМИ ставят основной задачей увеличение прибыли, а значит удовлетворение читательского спроса. Они снижают собственную идеологическую нагрузку и стараются максимально соответствовать желаниям своих потребителей. Они перестраивают свой новостной и общемедийный контент для того, чтобы стимулировать спрос со стороны читателей. Также определенная часть медийной площади обязательно распределяется на рекламные материалы. И даже если они выпускаются с соответствующими пометками (например, «На правах рекламы») все равно у читателя возникает ощущение, что он постоянно видит только «продающие тексты», и даже обычные журналистские статьи он начинает воспринимать как размещенные за деньги. Это в свою очередь стимулирует его собственные потребительские чувства и прагматический интерес, в частности, к политической сфере. Прочитав серию рекламных или коммерчески ориентированных материалов ему проще аналогичным образом воспринимать и тексты про политиков. Следовательно, это создает предпосылки для формирования прагматического настроя в области политического выбора.

Медиафактор конвергенции приводит к тому, что одна и та же новость доносится до читателя разнообразными способами. Таким образом, человек слышит одну и ту же информацию несколько раз, более того, он видит различные ее аспекты, постоянно узнает дополнительные подробности. За счет разнообразных способов передачи сведения усваиваются намного лучше и запоминаются надолго. Это приводит к тому, что любые переданные через СМИ тренды остаются в общественном сознании на многие годы. В транслируемой несколькими способами информации читатель, идя по пути наименьшего сопротивления, усваивает только самое простое. Конечно, дефицит информации скорее вреден для общественного развития, но его плюсом является то, что он заставляет относится к ней как некой ценности. А вот избыток данных заставляет человека придирчиво выбирать только самое-самое - и, как правило, он останавливается на самом легком и зрелищном. Таким образом, он ищет и находит наиболее легкие для усвоения формы, и переносит это отношение на всю получаемую им информацию. В его глазах мир политики выглядит в большей степени как некоторый спектакль, нежели борьба идеологических платформ. Это приводит к снижению общей идеологической составляющей в общественном сознании.
В пользу этих утверждений говорит и появление ряда тенденций, которые были отмечены автором на основании современных российских политологических исследований. Так, СМИ подстраивают имидж политиков под запрос целевой аудитории. Он становится более рыночным, т. е. удовлетворяющим интересам большинства избирателей. Средствам массовой информации проще продвигать политиков как товар, отчасти из-за отмеченной выше материальной составляющей. Самим претендентам на высокие должности такой подход кажется разумным и удобным [12]. Политический процесс часто выглядит в зеркале медиа как шоу. Пытаясь привлечь как можно больше читателей, СМИ приносят на политическое поле законы кинематографа и шоу-бизнеса. И поскольку эта игра начинает развиваться и затягивать все больше участников - сначала в нее включаются читатели, а затем и сами политики, и даже ученые, изучающие политические процессы.

Начинает активно развиваться так называемая гражданская журналистика Благодаря постоянному расширению медиаполя в него начинают попадать новые люди, формироваться новые жанры - например, блоги. В сфере политической журналистики это сдвигает вектор общественного восприятия с позиций официальной идеологии в сторону субъективизма, что в итоге является прямым следствием медиафакторов интергетизации и конвергеции.

Соответственно, можно предположить не только существование медиафакторов, но и их влияние на политическую консьюмеризацию. Оно обусловлено воздействием на обе стороны властных отношений: управляюшую и управляемую. Медиа служат площадкой для диалога этих сил и поэтому меняют вектор самой коммуникации. Новизна изучаемого предмета не позволяет проследить развитие медиафакторов на длительном отрезке времени, однако даже относительно краткосрочное наблюдение, что они оказывают стимулирующее влияние на политический консьюмеризм. 


\section{Библиография}

1. Балынская, Н. Р. Специфика участия средств массовой информации в политическом процессе в современной России: дисс. д-ра полит. наук. - Екатеринбург, 2009. - 290 с.

2. Борисов, Б. Л. Технологии рекламы и PR / Б. Л. Борисов. - М.: ФАИР-пресс, 2001. - 624 с.

3. Бьюкенен, Дж. Избранные труды. Серия: «Нобелевские лауреаты по экономике». Т. 1. - М.: Таурус Альфа, 1997. - C. 15-30.

4. Вартанова, Е. Л. Медиаэкономика зарубежных стран/ Е. Л. Вартанова. - М.: Аспект Пресс, 2003. - 334 с.

5. Корконосенко, С. Г. Основы теории журналистики/ С. Г. Корконосенко. - СПб: СПБГУ, 1995. - 87 с.

6. Луман, Н. Власть/ Н. Луман; пер. с нем. А. Ю. Антоновского. - М.: Праксис, 2001. - 256 с.

7. Прохоров, Е. П. Введение в теорию журналистики / Е. П. Прохоров. - М.: Рип-Холдинг, 2000. - 308 с.

8. Пшизова, С. Н. От «гражданского общества» к «сообществу потребителей»: политический консьюмеризм в сравнительной перспективе / С. Н. Пшизова // Полис. - 2009. - № 1. - С. 100-117.

9. Розина, В. А. Влияние институализации медиарынка на развитие политической консьюмеризации // Социально-гуманитарные знания. - 2016. - № 3. - С. 317-322.

10. Розина, В. А. Роль СМИ в консьюмеризации политической сферы жизни: дисс. канд. полит. наук. - Москва, 2013. - 255 с.

11. Российская периодическая печать: состояние, тенденции и перспективы развития. Отраслевой доклад ФА по печати и массовым коммуникациям [Электронный pecypc]. - Режим доступа: http://www.fapmc.ru/ rospechat/activities/reports/2011/item3.html (дата обращения: 01.11.2018).

12. Татаринова, Ю. Н. Современная российская политическая элита: имидж в электоральных предпочтениях: дис. ... канд. полит. наук. - Москва, 2013. - 257 с.

13. Buchanan J. et al. The Calculs of Consent / J. Buchanan, G. Tullock, - Ann Arbor: University of Michigan Press, 1962. $-70 \mathrm{p}$.

14. Downs, A. An Economic Theory of Democracy. - New York: Harper and Row, 1957. - 310 p.

\section{References}

1. Balynskaya N. R. Spetsifika uchastiya sredstv massovoi informatsii v politicheskom protsesse v sovremennoi Rossii. Diss. dokt. polit. nauk [The specifics of the participation of the media in the political process in modern Russia. Dr. polit. sci. diss.]. Ekaterinburg, 2009, 290 p.

2. Borisov B. L. Tekhnologii reklamy i PR [Advertising and PR technologies]. M.: FAIR-press, 2001, p. 624.

3. B'yukenen Dzh. Izbrannye trudy. Seriya: «Nobelevskie laureaty po ekonomike» [Selected Works. Series: Nobel laureates in economics]. M.: Taurus Al'fa, 1997, pp.15-30.

4. Vartanova E. L. Mediaekonomika zarubezhnyh stran [Media Economics of foreign countries]. M.: Aspekt Press, 2003, p. 334.

5. Korkonosenko S. G. Osnovy teorii zhurnalistiki [Fundamentals of the Theory of Journalism]. SPb: SPBGU, 1995, p. 87.

6. Luman N. Vlast [Power]. M.: Praksis, 2001, p. 256.

7. Prokhorov E.P. Vvedenie v teoriyu zhurnalistiki [Introduction to the theory of journalism]. M.: Rip-Holding, 2000, 308 p.

8. Pshizova S.N. Ot «grazhdanskogo obshchestva» k «soobshchestvu potrebitelei»: politicheskii kons'yumerizm v sravnitel'noi perspective [From «civil society» to «consumer community»: political consumerism in a comparative perspective]. Polis [Polis], 2009, I. 1, pp. 100-117.

9. Rozina V. A. Vliyanie institualizatsii mediarynka na razvitie politicheskoi kons'yumerizatsii [Influence of institutionalization of the media market on the development of political consumerization]. Sotsial'no-gumanitarnye znaniya [Socio humanitarian knowledge], 2016, I. 3, pp. 317-322.

10. Rozina V. A. Rol' SMI v kons'yumerizatsii politicheskoi sfery zhizni. Diss. cand. polit. nauk [The role of the media in the consummation of the political sphere of life. Dr. polit. sci. diss]. Moscow, 2013. 255 p.

11. Rossiiskaya periodicheskaya pechat': sostoyanie, tendentsii i perspektivy razvitiya. Otraslevoi doklad FA po pechati i massovym kommunikatsiyam [Russian periodicals: state, trends and development prospects. The industry report of the FA on the press and mass communications]. Available at: http://www.fapmc.ru/ rospechat/activities/reports/2011/ item3.html (accessed 01.09.2018).

12. Tatarinova Yu.N. Sovremennaya rossiiskaya politicheskaya elita: imidzh v elektoral'nykh predpochteniyakh. Diss. cand. polit. nauk [Modern Russian political elite: image in electoral preferences. Dr. polit. sci. diss], Moscow, 2013, 257 p.

13. Buchanan J., Tullock G. The Calculs of Consent. Ann Arbor: University of Michigan Press, 1962, p. 70.

14. Downs A. An Economic Theory of Democracy. New York: Harper and Row, 1957, p. 310. 